\title{
MULTI-SCALE CHANGE ANALYSIS OF SEA ICE EXTENT IN ARCTIC
}

\author{
X. Liu ${ }^{1,2}$, H. Chen ${ }^{1,2}$, T. Feng ${ }^{1,2 *}$ \\ ${ }^{1}$ Center for Spatial Information Science and Sustainable Development Applications, Tongji University, Shanghai, China, \\ ${ }^{2}$ College of Survey and Geo-Informatics, Tongji University, Shanghai, China, - (14xiaomin, 24chz, fengtiantian)@ tongji.edu.cn
}

Commission CommissionIII,WG III/9

KEY WORDS: Arctic, Sea Ice Extent, Multi-Scale, Change Analysis, Melting Rate, Change Cycle

\begin{abstract}
:
The extent of polar sea ice is one of the key parameters of cryosphere and polar environmental change, which plays an important role in the study of global climate change. In this paper, the monthly product of sea ice extent, recorded from 1979 to 2016 , was selected to analysis the change characteristics in multi time scales, which are annual, seasonal and monthly. It is found that the sea ice in Arctic was melting continuously for past four decades. And the melting rate was accelerated significantly since 2000. Furthermore, the Arctic was divided into thirteen sub-regions, and the change mechanism of sub-regions was discussed. Different change trends for sub-regions in four seasons were presented. Four active sub-regions were found, and the periodical analysis with the method of wavelet analysis was further carried out. The results show that the changes in the four active regions are periodic and the change period is over 10 years during the period from 1979 to 2016.
\end{abstract}

\section{INTRODUCTION}

The extent of polar sea ice is one of the key parameters of cryosphere and polar environmental change, which plays an important role in the study of global climate change. The extent of Arctic sea ice shows obvious decreasing trend with the approximate loss of $13.3 \%$ per decade, comparing with the mean extent in September during the period from 1981 to 2010 (Serreze and Stroeve, 2015). It is predicted that Arctic sea ice extent will continue to decrease significantly in the coming decades. In order to respond to the reduction of arctic sea ice timely, it is of great necessary to describe the correlation and mechanism of Arctic sea ice extent changes in long-term, medium-term and short-term exactly.

There are several methods to obtain sea ice extent based on characteristics of sea ice using different satellite remote sensing data. For example, it is widely used to detect sea ice based on reflection characteristics using visible and infrared satellite imagery. This method could separate sea ice from open water with high effectiveness. However, both the misidentification of cloud and new sea ice and the effectiveness with insufficient illumination are major difficulties (Laura Siitam, 2017; Riggs et al., 1999; Wand et al., 2017 ). In order to deal with this difficulties, some researchers detect sea ice according to the ice surface temperature (IST) derived from Advanced Very High Resolution Radiometer (AVHRR) data carried on Moderate Resolution Imaging Spectroradiometer (MODIS) satellite, which is not depended on the illumination, and effective during nighttime. However, the accuracy of IST retrievals will be lower when it is cloudy (Kang et al., 2014; Kilpatrick et al., 2015; Riggs et al., 1999). Different from AVHRR data, passive microwave remote sensing data could extract sea ice on all sky conditions based on polarization difference and brightness temperature difference. But the low identification accuracy of the ice cover over small inland water bodies and along the coastal line couldn't be ignored, limited to the coarse resolution and confusion of mixed land-water scenes with water scenes having small concentration of ice (Comiso et al., 1997; Garrity et al., 2002; Romanov, 2017; TONBOE and TOUDAL, 2005). Moreover, Synthetic aperture radar (SAR) satellite data shows great advantages for sea ice extraction thanks to high spatial resolutions and independence of illumination and sky conditions, which works well for monitoring sea ice with methods such as co-polarization ratio, penetration depth, scattering entropy and polarization difference. But lower accuracy of identification of thin, low concentration and melting ice and limited to the incidence angles are the challenge (Casey et al., 2016; Johansson et al., 2017). In addition, spaceborne LiDAR measurement data under clear sky conditions, such as CALIOP LiDAR, can also be used to study sea ice cover based on the relationship of colour ratio and depolarization ratio, since it has reliable measurements during all-day at low solar angles through considerable aerosol loads thin clouds ( $\mathrm{Lu}$ et al., 2017).

In this paper, the extent product with spatial resolution of $25 \mathrm{~km}$ $\times 25 \mathrm{~km}$ (Fetterer et al., 2017), downloaded from the website of the National Snow and Ice Data Center (NSIDC), was selected for the change analysis in recent four decades. The data resources of this product include Scanning Multi-channel Microwave Radiometer (SMMR), Special Sensor Microwave Imager (SSM/I) and Special Sensor Microwave Imager/Sounder (SSMIS). It is available and produced in a consistent way that make the time-series appropriate for use when paying attention to long-term trend in sea ice cover about 40 years. The change characteristics were described in multiple time scales, such as seasonal, annual, and decade. And the analysis results were presented in Section 3.

* Corresponding author: T. Feng (fengtiantian@tongji.edu.cn) 


\section{METHODS FOR CHANGE ANALYSIS OF SEA ICE EXTENT}

In order to estimate the change characteristics of sea ice extent in Arctic, both change trend and change cycle are analysed in this Section. Change trend, which can indicate the rate of accumulate or retreat of sea ice over a specific period, is calculated according to sea ice extent data in various time scales, including annual, seasonal and monthly. What's more, the Arctic is divided into sub-regions, and the change trends in subregions are further discussed. The change cycle, which can reveal the periodic pattern of sea ice, is performed in several active sub-regions by using wavelet analysis method.

\subsection{Fitting of linear trend}

The linear trend of sea ice extent is calculated by using the least-squares method. Suppose that $X(i)$ is the sea ice extent in Arctic at time $t(i)(i=1,2,3 \ldots \mathrm{n})$, the linear change trend $C T$ is estimated by equation (1) (Stepniak, 2011):

$$
C T=\left(\sum_{i=1}^{n} X_{i} t_{i}-\sum_{i=1}^{n} X_{i} \sum_{i=1}^{n} t_{i} / n\right) \sum_{i=1}^{n} t_{i}^{2}-\left(\sum_{i=1}^{n} t_{i}\right)^{2} / n
$$

The sign (positive or negative) of $C T$ indicates an accumulation or retreat trend of sea ice. And the magnitude of $C T$ indicates the rate of change.

\subsection{Estimation of change cycle}

Considering the change trend in long-term, the change of sea ice extent has a certain periodic signal, accompanying by randomness, mutability and "multi-time scale" structure. Wavelet analysis is one of effective ways to explore the periodic information hiding in the time sequence data in different time scales. The basic idea of wavelet analysis is to express or approximate a signal with a cluster of wavelet functions. As a result, the wavelet function is the key of wavelet analysis, which refers to the function that are oscillatory and can be attenuated rapidly to zero, as described in equation (2) (Zayed, 2011):

$$
\int_{-\infty}^{+\infty} \varphi(t) d t=0
$$

where $\varphi(t)=$ the base wavelet function

Then, the base wavelet function can form a cluster of wavelet functions by scaling the scale and shifting the time axis, as shown equation (3) (Zayed, 2011):

$$
\varphi_{a, b}(t)=|a|^{-1 / 2} \varphi\left(\frac{t-b}{a}\right) d t
$$

where

$$
\begin{aligned}
& \varphi_{a, b}(t)=\text { the wavelet function } \\
& a=\text { the scale factor } \\
& b=\text { the translation factor }
\end{aligned}
$$

\section{RESULTS AND DISCUSSION}

The results of annual, seasonal, monthly change trend are calculated according to equation (1). It is shown that the sea ice extent in Arctic has decreased $2.14 \times 10^{6} \mathrm{~km}^{2}$ from 1979 to
2016, and the average melting rate is $5.35 \times 10^{4} \mathrm{~km}^{2} / \mathrm{y}$. The annual anomaly of sea ice extent is defined as the difference between sea ice extent in a particular year and average sea ice extent from 1979 to 2016. The piecewise curve fitting strategy is adopted when using equation (1), considering that the trend of anomalies change shows differences obviously. As shown in Figure 1, the anomalies curve turns to negative Since 2000, and the average melting rate is $3.52 \times 10^{4} \mathrm{~km}^{2} / \mathrm{y}$ during the period from 1979 to 2000 . In contrast, the average melting rate is 6.78 $\times 10^{4} \mathrm{~km}^{2} / \mathrm{y}$ during the period from 2000 to 2016, which reveals that the melting rate of Arctic sea ice extent is accelerated significantly during recent 20 years.

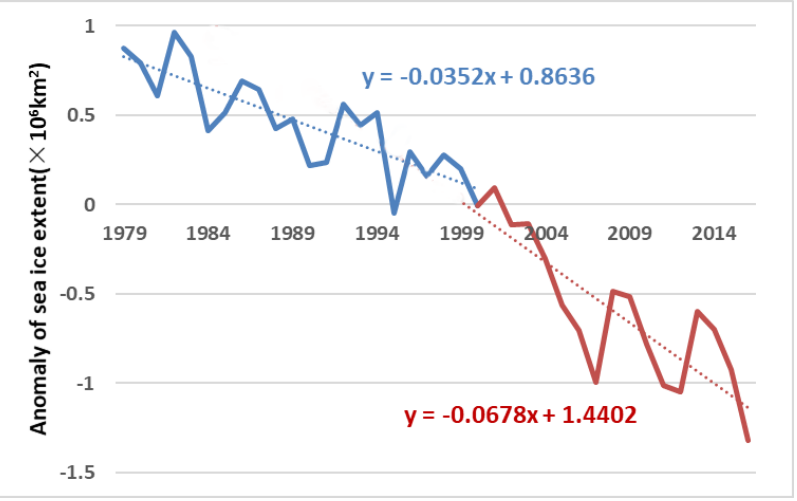

Figure 1. Annual anomaly of sea ice extent in Arctic from 1979 to 2016

There are various technical definitions of seasons in Arctic. According to (Xia et al., 2014), it is defined that spring is from April to June, summer is from July to September, autumn is from October to December, and winter is from January to March. In figure 2, the seasonal change trends of sea ice extent in Arctic are presented. It is shown that sea ice is melting in all seasons, and the melting rate is $7.85 \times 10^{4} \mathrm{~km}^{2} / \mathrm{y}$ in summer, which is the fastest season in a year.

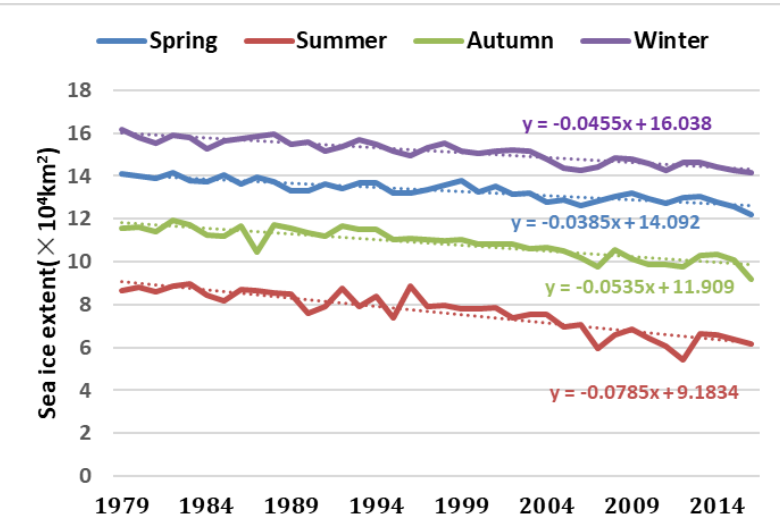

Figure 2. Seasonal change trend of sea ice extent in Arctic from 1979 to 2016

The monthly change trend from 1979 to 2016 is shown in Table 1 and Figure 3. It is shown that the sea ice extent is the largest in March, while smallest in September. On the other hand, the fastest melting rate appears in September, while the slowest melting rate appears in May. 


\begin{tabular}{|c|c|c|c|c|c|c|}
\hline Month & Jan. & Feb. & Mar. & Apr. & May & Jun. \\
\hline $\begin{array}{c}\text { Melting } \\
\text { rate } \\
\left(10^{4} \mathrm{~km}^{2} / \mathrm{y}\right)\end{array}$ & 4.64 & 4.63 & 4.17 & 3.72 & 3.40 & 4.44 \\
\hline $\begin{array}{c}\text { Month } \\
\begin{array}{c}\text { Melting } \\
\text { rate } \\
\left(10^{4} \mathrm{~km}^{2} \mathrm{y}\right)\end{array}\end{array}$ & 7.25 & 7.60 & 8.71 & 6.60 & 5.51 & 4.64 \\
\hline
\end{tabular}

Table 1. Monthly melting rate of sea ice extent in Arctic from 1979 to 2016

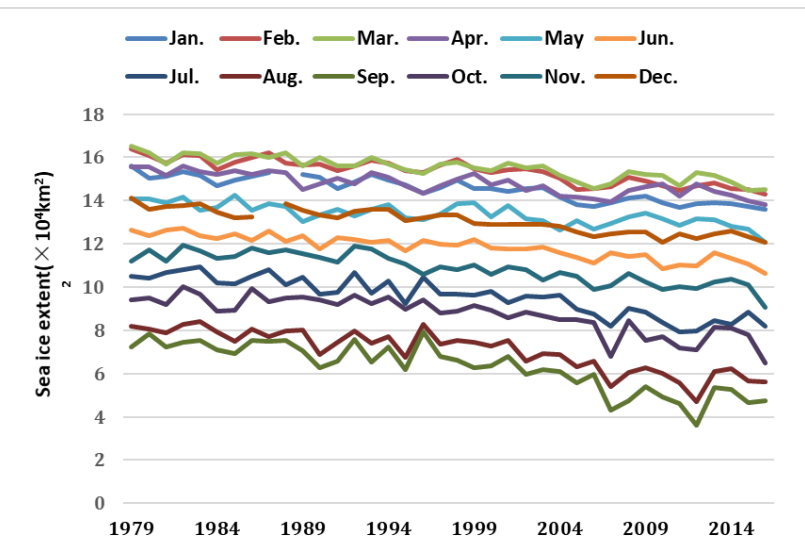

Figure 3. Monthly change trend of sea ice extent in Arctic from 1979 to 2016

In order to analysis the change characteristics of sea ice extent in Arctic in detail, the Arctic is divided into 13 regions according to (Xia et al., 2014; Fetterer et al.,2017), as shown in Figure 4. The total reduction of Arctic sea ice in 13 regions from 1979 to 2016 is presented in Figure 5.

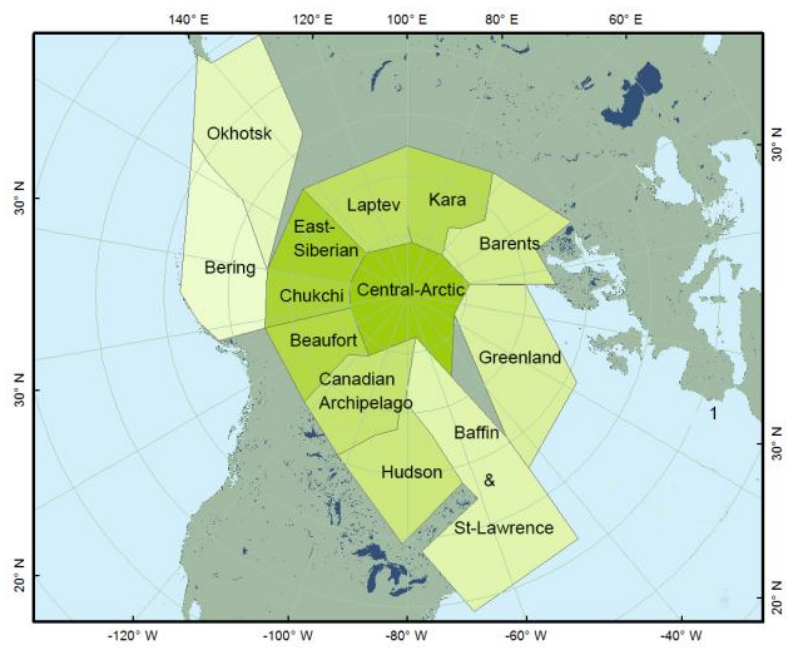

Figure 4. Distribution of 13 regions in Arctic

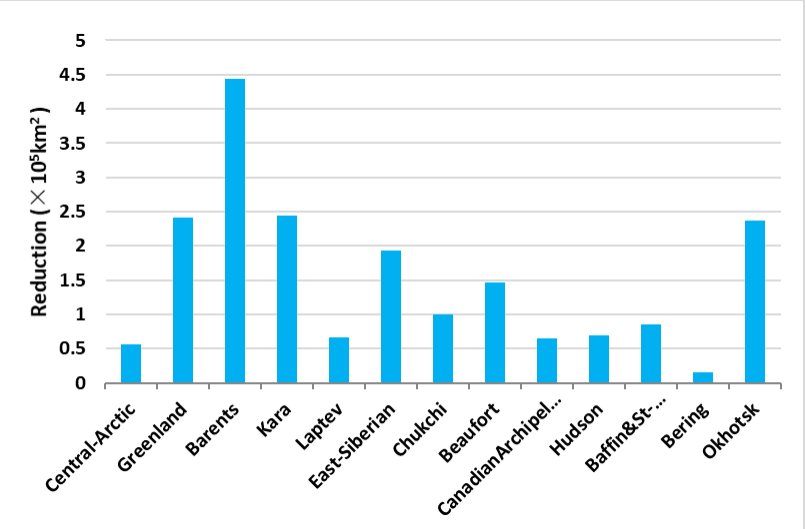

Figure 5. The total reduction of sea ice extent of 13 regions in Arctic from 1979 to 2016

Besides the annual melting rate, the standard deviation of sea ice extent in each region is also be considered, which can indicate the divergence between the data of sea ice extent and the trend line fitted by equation (1). The melting rate and corresponding standard deviation of 13 regions in Arctic during both melting period (spring and summer) and freezing period (autumn and winter) are shown in Figure 6. It is found that the sea ice in Barents, Greenland, Okhotsk and Baffin \& StLawrence is more active than other regions.

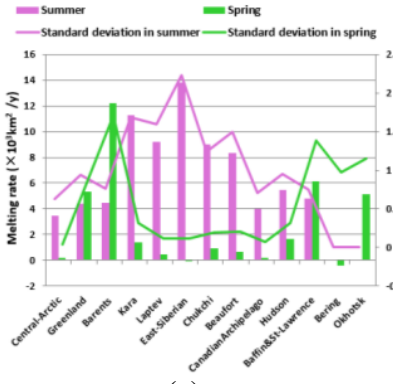

(a)

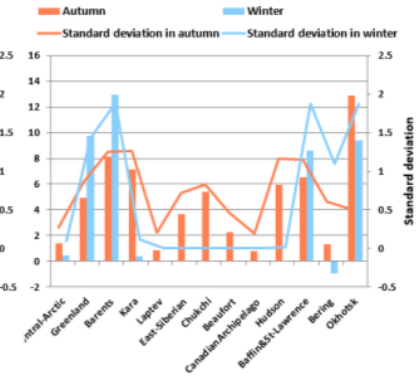

(b)
Figure 6 . The melting rate and corresponding standard deviation of 13 regions in Arctic during (a) melting period and (b) freezing period

The change cycles of these four active regions are further investigated based on wavelet analysis. The results are shown in Figure 7. Based on the wavelet graph of real part coefficient and energy significant area in Figure 7(a), it is indicated that there is a cyclical swing in time scale of $6 \sim 8$ years and $20 \sim 25$ years during the period from 1979 to 2016 in Barents. At the same time, the periodic oscillation is hidden under the time scale of 12 17 years from 1979 to 1997. Similarly, we can find a cyclical swing in the time scales of $20 \sim 23$ years and $26 \sim 28$ years in Greenland. And there is hidden the periodic oscillation in time scale of $13 \sim 17$ years from 1979 to 2000. In Baffin \& Lawrence, there are periodic oscillations at the time scale of 25 30 years in the whole time domain from 1979 to 2016 . Meanwhile, in the period from 1979 to 1995 , the period under the time scale of 12 15 years is hidden, but the oscillation is less significant. Finally, there are periodic oscillations at the time scale of 13 18 years in the whole time domain from 1979 to 2016 in Okhotsk. 

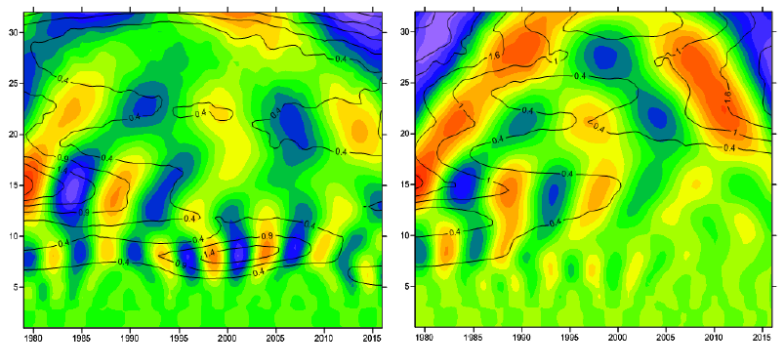

(a)
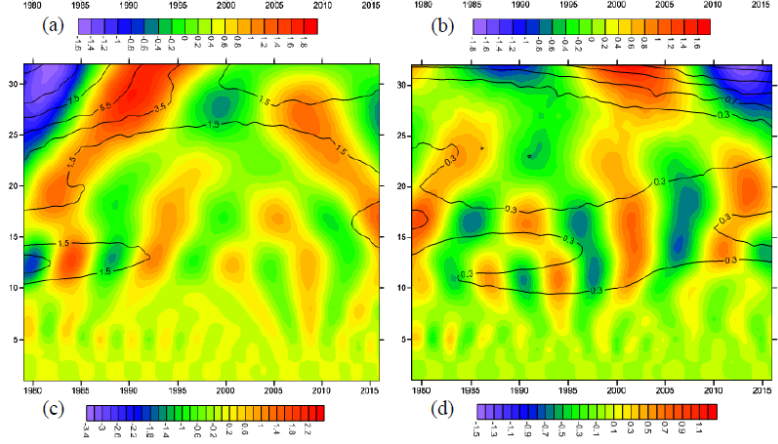

Figure 7. Wavelet analysis results for change cycle of sea ice extent in (a) Barents, (b) Greenland, (c) Baffin \& Lawrence and (d) Okhotsk

\section{CONCLUSION}

The change characteristics, including change trend and change cycle, of sea ice extent in Artic during the period from 1979 to 2016 are presented in this paper. It is shown that the sea ice extent is reducing continually. And the annual melting rate accelerated significantly since 2000. According to the analysis of the variation trend of sea ice of sub-regions in Arctic, four regions, which are Barents, Greenland, Okhotsk, and Baffin \& St-Lawrence are more active, while Bering, Central-Arctic and Canadian Archipelago are relatively stable. With the wavelet analysis of four active regions, the changes of the four regions are periodic and the change period is over 10 years generally. For the further research, we will focus on the extraction method of sea ice in active areas by using multi-source high-resolution remote sensing data.

\section{ACKNOWLEDGEMENTS}

Acknowledgement of support for The National Key Research and Development Program of China (2017YFA0603104) is welcome.

\section{REFERENCES}

Casey, J.A., Howell, S.E.L., Tivy, A. and Haas, C., 2016. Separability of sea ice types from wide swath C- and L-band synthetic aperture radar imagery acquired during the melt season. Remote Sensing of Environment, 174, pp. 314-328.

Comiso, J.C., Cavalieri, D.J., Parkinson, C.L. and Gloersen, P., 1997. Passive microwave algorithms for sea ice concentration: A comparison of two techniques. REMOTE SENS. ENVIRON, 60(3), pp. 357-384.

Fetterer, F., K. Knowles, W. Meier, M. Savoie, and A. K. Windnagel., 2017, updated daily. Sea Ice Index, Version 3. [Indicate subset used]. Boulder, Colorado USA. NSIDC: National Snow and Ice Data Center. doi: http://dx.doi.org/10.7265/N5K072F8
Garrity, C., Dan, L., Kern, S. and Pedersen, L.T., 2002. Linescan camera evaluation of SSM/I $85.5 \mathrm{GHz}$ sea ice retrieval. Remote Sensing of Environment, 83(3), pp. 472-487.

Johansson, A.M., Brekke, C., Spreen, G. and King, J.A., 2017. $\mathrm{X}-, \mathrm{C}-$, and L-band SAR signatures of newly formed sea ice in Arctic leads during winter and spring. Remote Sensing of Environment, 204, pp. 162-180.

Kang, D., Im, J., Lee, M.I. and Quackenbush, L.J., 2014. The MODIS ice surface temperature product as an indicator of sea ice minimum over the Arctic Ocean. Remote Sensing of Environment, 152, pp. 99-108.

Kilpatrick, K.A., Podestá, G., Walsh, S., Williams, E., Halliwell, V., Szczodrak, M., Brown, O.B., Minnett, P.J., Evans, R., 2015. A decade of sea surface temperature from MODIS. Remote Sensing of Environment, 165, pp. 27-41.

Laura Siitam, L.S.O.P., 2017. Statistical characterization of the sea ice extent during different winter scenarios in the Gulf of Riga (Baltic Sea) using optical remote-sensing imagery. International Journal of Remote Sensing, 38(3), pp. 617-638.

Lu, X., Hu, Y., Liu, Z., Rodier, S., Vaughan, M., Lucker, P., Trepte, C., and Pelon, J., 2017. Observations of Arctic snow and sea ice cover from CALIOP lidar measurements. Remote Sensing of Environment, 194, pp. 248-263.

Riggs, G.A., Hall, D.K. and Ackerman, S.A., 1999. Sea Ice Extent and Classification Mapping with the Moderate Resolution Imaging Spectroradiometer Airborne Simulator. REMOTE SENS. ENVIRON, 68, pp.152-163.

Romanov, P., 2017. Global Multisensor Automated satellitebased Snow and Ice Mapping System (GMASI) for cryosphere monitoring. Remote Sensing of Environment, 196, pp. 42-55.

Serreze, M.C. and Stroeve, J., 2015. Arctic sea ice trends, variability and implications for seasonal ice forecasting. Philos Trans A Math Phys Eng Sci, 373(2045).

Stepniak, C., 2011, A Representation of Nonhomogeneous Quadratic Forms with Application to the Least Squares Solution. MATHEMATICAL PROBLEMS IN ENGINEERING, 2011, pp. $1-5$.

TONBOE, R. and TOUDAL, L., 2005. Classification of newice in the Greenland Sea using Satellite SSM/I radiometer and SeaWinds scatterometer data and comparison with ice model. Remote Sensing of Environment, 97(3), pp. 277-287.

Wand, X.D., Wu, Z.K., Wang, C., Li, X.W. and Li, X.G., 2017. Reducing the Impact of Thin Clouds on Arctic Ocean Sea Ice Concentration from FengYun-3 MERSI Data Single Cavity. IEEE, 5, pp. 16341-16348.

Xia, W., Xie, H. and Ke, C., 2014. Assessing trend and variation of Arctic sea-ice extent during 1979-2012 from a latitude perspective of ice edge. Polar Research, 33.

Zayed, J.C.I., 2011. Wavelets and Multiscale Analysis. Birkhäuser Boston, pp. 1-65 